DOI: 10.12731/2070-7568-2017-1-39-52

УДК 327.5

\title{
ФАКТОРЫ УСИЛЕНИЯ \\ ТЕРРОРИСТИЧЕСКОЙ АКТИВНОСТИ ГРУППИРОВКИ «ИСЛАМСКОЕ ГОСУДАРСТВО» НА ТЕРРИТОРИИ ЕВРОПЕЙСКОГО СОЮЗА
}

\section{Лобанов Н.А.}

Начало ХХІ века ознаменовало собой усиление процессов глобализации и интеграции во всем мире. Это привело к тому, что международное сообщество, в особенности европейские государства, столкнулось с рядом новых угроз распространения исламистского терроризма, наиболее актуальной из которых является деятельность группировки «Исламское государство» (ИГ). В этом контексте важно определить причины интенсивного роста активности «ИГ» и его влияния на территории Евponbl.

В статье проводится анализ факторов, способствующих распространению терроризма, а также приводится ряд рекомендаций, выполнение которых, по мнению автора, могут привести к снижению уровня террористической угрозы.

Цель исследования - выявить факторы усиления влияния организации «Исламское государство» и увеличения числа террористических атак в европейских государствах.

Автор приходит к выводу, что проблема «ИГ» представляет собой комплексную угрозу, для предотвращения которой необходим ряд усилий как внутри европейского континента, так и на территории Ближнего Востока, требующих системного подхода и высокого уровня консолидации и координации международного сообщества.

Ключевые слова: терроризм; исламизм; Исламское государство; Европа; Ближний Восток. 


\section{FACTORS IN STRENGHTNING OF TERRORIST ACTIVITY OF "ISLAMIC STATE" GROUPING ACROSS EUROPEAN UNION}

\section{Lobanov N.A.}

XXI century was marked by the strengthening of globalization and integration processes in whole world. This led to the fact that the international community, especially European countries, faced the number of new threats to the spread of Islamic terrorism, the most urgent of which is the activity of "Islamic State" grouping. In this context it's important to determine the reasons of intense activity growth of IS and its influence in Europe.

The article analyzes the factors, contributing to the spread of terrorism. Also it gives some recommendations, implementation of which, according to the author, could decrease the level of terrorist threat.

The purpose of the research is to determine factors of growing influence of "Islamic State" and increasing number of terrorist attacks in European countries.

The author concludes that IS problem is a comprehensive threat, to prevent which a number of efforts - both within the European continent and in Middle East - is required. It also requires a systematic approach and a high level of consolidation and coordination within the international community.

Keywords: terrorism Islamism; Islamic State; Europe; Middle East.

Глобализационные процессы, оказывающие влияние на все государства международного сообщества, несмотря на объективные положительные изменения, привнесли с собой и ряд отрицательных последствий. С одной стороны, можно наблюдать ряд масштабных изменений, которые привели к образованию крупных информационно-экономических пространств, а с другой - образование актуальных, связанных с распространением терроризма угроз и проблем, которые стоят перед мировым сообществом. Так, 
по словам проф. И.Л. Морозова: «Информационный мир порождает террористов нового типа как психологической, так и боевой подготовки» [1, с. 11]. В настоящий момент, террористическая организация «Исламское государство» признается одной из наиболее опасных угроз системе международной безопасности. Провозгласив собственное квазигосударство на занятых им территориях Ирака и Сирии в 2013 году, ИГ взяло на себя роль «флагмана» мирового джихадистского движения, затмив собой «Аль Каеду». Данная организация обозначила своей целью создание исламского халифата на территориях Ирака и Леванта (Шама) [2], который также включает в себя территории Сирии, Ливана, Израиля, Палестины, Иордании, Турции, Кипра и Египта, и на данный момент «ИГ» является одним из наиболее активных участников сирийского конфликта. Однако, сфера деятельности и влияния «Исламского государства» простирается далеко за границы Ближнего Востока.

Разрастание сирийского конфликта и террористической активности «ИГ» довольно значительно затронуло и европейский континент. Согласно статистике, с 2015 года количество террористических актов, устроенных исламистами в Европе, увеличилось кратно. Только в 2015-2016 гг. жертвами терактов в Европе стало более 300 человек, а наиболее резонансными инцидентами стали события во Франции, Бельгии, Германии и Турции.

Так, 7 января 2015 г. вооруженные террористы ворвались в редакцию сатирического журнала Charlie Hebdo в Париже, убив 12 человек и ранив 11 [3]. Формально, основным поводом для нападения послужило издание журналом карикатур на пророка Мухаммада. О своей причастности к теракту заявили группировки «АльКаида на Аравийском полуострове» и «Исламское государство».

Одним из наиболее масштабных инцидентов стала серия атак террористов-смертников в различных частях Парижа 13 ноября 2015 г. В ходе террористической акции боевиками было приведено в действие несколько взрывных устройств и совершены расстрелы мирных жителей, в результате которых погибло 130 человек [4]. Как и ранее, ответственность за преступления взяло на себя «ИГ». 
22 марта 2016 г. после задержания одного из организаторов ноябрьских терактов в Париже, Салаха Абделслама, в брюссельском аэропорту и метро прогремели взрывы, в результате которых погибло 35 человек [5].

Следующей масштабной акцией «Исламского государства» стало нападение террориста-одиночки, который, управляя грузовиком, врезался в толпу мирных жителей на пляже в Ницце 14 июля 2016 года [6]. Жертвами теракта стали 84 человека. Аналогичным образом был совершен наезд на посетителей рождественской ярмарки в Берлине в декабре этого же года, в ходе которого погибло 12 человек [7].

Террористическая активность исламистов нарастает не только в странах Евросоюза, но и в государствах, стремящихся войти в него. Последним крупным терактом на данный момент стал расстрел посетителей ночного клуба Стамбула 1 января 2017 г., где террористодиночка убил около 40 человек [8]. Как и в предыдущих случаях, ответственность за содеянное взяла на себя организация «ИГ».

Среди последних терактов прослеживается тенденция к тому, что действующей силой становятся террористы-одиночки, зачастую не использующие оружия или взрывчатые вещества. Очевидно, что подобная тактика крайне усложняет процесс выявления, отслеживания и предотвращения террористических актов. К тому же, организация подобных акций практически не требует крупных финансовых затрат. Вдобавок подавляющее большинство ответственных за теракты преступников ранее было либо замечено за совершением противоправных действий, либо являлось участниками террористических ячеек, что указывает на несовершенство правоохранительных систем европейских стран. Растущая угроза со стороны столь активной террористической организации, как «Исламское государство», требует выявления и исследования факторов, повлиявших на ее усиление.

В первую очередь основным фактором, влияющим на рост нестабильности в Европе, является критическое увеличение числа мигрантов из стран Ближнего Востока. Согласно статистическим 
данным ОЭСР, с 2013 по 2015 гг. приток мигрантов увеличился практически в три раза - с 556880 до 1534106 человек соответственно [9]. При этом основная часть приходится на беженцев из Сирии, Афганистана и Ирака. Соответственно с увеличением притока мигрантов растет и опасность попадания на территорию Европы потенциальных террористов из стран Ближнего Востока, Северной Африки и Средней Азии. Так, по словам министра внутренних дел Германии Томаса де Мезьера, только на территории страны находится как минимум «520 потенциальных боевиковджихадистов и 360 человек, состоящих в связях с потенциальными террористами» [10]. В то же время глава ФСБ, выступая на открытии 15-го совещания руководителей спецслужб, органов безопасности и правоохранительных органов, заявил: «Ни для кого не секрет, что взрывной рост числа мигрантов с Ближнего Востока и Северной Африки дестабилизирует социально-политическую и резко ухудшает криминогенную обстановку во многих странах, в значительной степени увеличивает масштаб оперативной работы для спецслужб и правоохранительных органов, заставляет работать нас в особом режиме» [11].

О присутствии на территории Евросоюза большого количества потенциальных террористов говорят и сами арестованные боевики. По свидетельствам Гарри Сафро, прошедшего обучение в лагерях террористов «ИГ», в организации даже существует специальная структура под названием «Эмни», которая занимается вопросами проведения терактов за рубежом [12]. Сафро также заявил, что в Европе уже сформировано множество террористических ячеек, действующие как координационные центры, которые рассылают приказы будущим террористам-смертникам.

В целом, европейские страны предпринимают попытки преодоления миграционного кризиса, однако ввиду отсутствия единых взглядов и стратегии, решение данной проблемы оказывается под угрозой.

Другим фактором, влияющим на рост террористической активности на территории Европы, представляется интенсивная про- 
паганда идеологии «Исламского государства», в том числе среди мусульманского населения Европы через различные социальные медиа и лояльные группировке СМИ. «ИГ» имеет в своем распоряжении и активно использует широкий спектр каналов донесения своих идей до потенциальных сторонников, в частности большое количество аккаунтов в Twitter, Facebook и YouTube, чей охват и специфика позволяют обращаться к наиболее активной части общества - молодежи. Немаловажным фактором в распространении идей «джихада» является регулярный выпуск лояльным медиаресурсом Al-Hayat Media Center, различных видеороликов и документальных фильмов. Помимо устрашающих видеозаписей со сценами казней пленных, был выпущен целый ряд роликов, повествующих об установлении социальной справедливости и благополучия на территориях, занятых «Исламским государством», а также духовном и экономическом упадке западной цивилизации, отвергая при этом ее экономическую модель и обвиняя в несправедливости, и лишении людей любых прав на имущество «дарованное им Аллахом» и называя ее «капиталистическим рабовладением». Таким образом, группировка в своей пропаганде задевает важную проблему - социальное расслоение, которое особенно заметно в среде мигрантов, чей уровень жизни разительно отличается от уровня жизни среднестатистического коренного европейца.

В силу своих внутренних особенностей мировое исламское сообщество не имеет единых взглядов на современное мироустройство, что влечет за собой отсутствие какой-либо единой идеологической платформы, на основе которой мусульмане всего мира могли бы создать легитимную политическую «трибуну», которая консолидировала и выражала бы их мнения и интересы как отдельного общества. В такой ситуации беженцы из Ближнего Востока, попадая в чужеродный культурный европейский социум, где отсутствуют какие-либо жесткие идейные ориентиры, оказываются в идеологическом «вакууме» и становятся весьма подвержены массивной исламистской пропаганде. В свою очередь «Исламское государство», благодаря развитой информационной сети и провоз- 
глашению себя защитником всех правоверных мусульман, успешно проводит политику привлечения новых членов в свои ряды. Стоит добавить, что такая пропагандистская тактика позволяет не только пополнять ряды боевиков в Сирии и Ираке, но и дает возможность вербовать потенциальных террористов на территории самой Европы, что крайне упрощает процесс подготовки террористических актов в европейских странах.

К одним из факторов распространения исламистского терроризма можно отнести и неразрешенный сирийский конфликт. Однако основным препятствием на пути к решению данной проблемы является различная трактовка путей урегулирования кризиса.

Коалиция, возглавляемая США, на протяжении всего конфликта настаивает на отстранении сирийского руководства во главе с Башаром Асадом и создании правительства, куда войдут представители так называемой «умеренной оппозиции», борющейся с режимом Асада. Однако и по сей день понятие «умеренной оппозиции» является довольно размытым, т.к. зачастую американской стороной под ним подразумевается такая группировка как «Джабхат Фатх аш-Шам», ранее известная как «Джабхат ан-Нусра» [13] - отделение «Аль-Каеды» в Сирии и Ливане, имеющая откровенно радикальные исламистские взгляды. Поддержка организаций такого рода существенно осложняет борьбу с терроризмом на Ближнем Востоке.

Вдобавок страны коалиции активно занимаются поставками вооружения и других ресурсов этой группе повстанцев. 10 сентября 2014 г. после заявления президента Обамы США начали несанкционированные авианалеты в Сирии, с целью борьбы с «ИГ» [14].

Напротив, Россия признает легитимным сирийское правительство, оказывает ему военно-техническую поддержку в борьбе с террористами. Еще одним важным фактором участия РФ в сирийском конфликте стало размещение российской авиационной группы на авиабазе Хмеймим по просьбе правительства Сирии осенью 2015 года [15]. С этого момента Российская Федерация оказывает военную поддержку авиацией сирийским правительственным войскам 
и проправительственным военизированным формированиям. Также поддержку сирийскому режиму оказывают Иран и Китай.

Стоит отметить, что помимо коалиции, возглавляемой США и России, на территории Сирии боевые действия осуществляются целым рядом обособленных друг от друга формирований различного происхождения. Так, свои военные операции против террористов без проведения каких-либо согласований вели Турция, Иран, курдская партия «Демократический союз», Сирийская свободная армия и группировка «Хезболла». Каждая из сторон данного конфликта по сути преследует собственные политические и военные цели, зачастую не всегда уделяя должное место борьбе с терроризмом, а порой и используя их в своих целях. Такая ситуация свидетельствует об отсутствии у международного сообщества единой стратегии по борьбе с террористической угрозой и решению сирийского конфликта, что в свою очередь ведет к негативным последствиям как на территории Ближнего Востока, так и в частности в Европе.

Одним из наиболее важных факторов, влияющих на активность «Исламского государство» является финансирование указанной организации. Согласно данным, опубликованным в докладе группы разработки финансовых мер борьбы с отмыванием денег (ФАТФ), основными каналами поступления финансовых средств «ИГ» по состоянию на февраль 2015 г. были [16]:

- нелегальная прибыль от оккупации территорий, включая ограбление банков, грабежи, контроль над нефтяными месторождениями и нефтеперерабатывающими заводами, а также хищение экономических активов и незаконное налогообложение товаров и наличных средств, проходящих транзитом через подконтрольную ИГИЛ территорию;

- похищение с целью выкупа;

- пожертвования, в том числе со стороны или при посредничестве некоммерческих организаций;

- материальная поддержка, например, поддержка, связанная с присутствием иностранных боевиков-террористов;

- привлечение средств через современные социальные сети. 
В докладе также указывается, что значимость каждого из перечисленных каналов может варьироваться в «зависимости от наличия экономических ресурсов и успеха военных усилий коалиции в борьбе с ИГИЛ».

Однако в силу отсутствия открытых данных, достоверно оценить размеры и соотношение всех финансовых поступлений в организацию не представляется возможным. Но стоит добавить, что помимо вышеперечисленных каналов, эксперты отмечают, что на первом этапе у группировки были «страны-доноры» в лице Катара, Саудовской Аравии и Турции [17]. Об участии Саудовской Аравии в спонсировании «ИГ» также свидетельствует переписка бывшего госсекретаря Хиллари Клинтон, опубликованная порталом WikiLeaks [18].

Таким образом, группировка «Исламское государство» представляет собой комплексную угрозу, для борьбы с которой необходимо принять ряд различных мер.

Во-первых, необходимо ограничить увеличивающиеся потоки мигрантов, в хаотичном порядке прибывающие на европейский континент. Для этого потребуется либо кратное уменьшение квот европейских стран на прием беженцев, либо полный запрет на въезд беженцев из Ближнего Востока, Северной Африки и Средней Азии. Это позволит снизить приток мигрантов, а вместе с ними и потенциальных террористов в Европу.

Во-вторых, следует разработать новую концепцию ассимиляции граждан, прибывших из ближневосточных стран, с учетом их культурных и религиозных особенностей.

Необходимым условием для противодействия исламистскому терроризму является расширение полномочий правоохранительных органов Европы и создание общеевропейской базы правонарушений мигрантов, а также введение системы специального учета перемещений мигрантов по территории Европы.

Как отмечает политолог Е.О. Васильчук: «в радикальных политических и политизированных структурах идеология играет исключительно важную роль, поскольку именно она выступает 
основным средством внутригрупповой мобилизации и рекрутирования новых активистов» [19, с. 9]. Для противодействия пропаганде джихадистских идей потребуется создать европейские мусульманские СМИ и интернет-медиа, с привлечением авторитетных исламских ученых и богословов для проведения разъяснительной работы среди мусульман Европы. Также будет полезен опыт Чеченской республики по проведению обучающих курсов для имамов с целью противостоять влиянию террористов на уровне прихода. Такие курсы включают в себя изучение четырех дисциплин: арабский язык, правильное чтение Корана, исламское право и вероубеждение [20].

Важным условием снижения террористической активности в том числе и в Европе, является физическое устранение боевиков «ИГ». Военная победа над группировкой будет достигнута только при условии полного объединения всех сторон конфликта, выступающих против террористов. Однако если такая объединяющая стратегия не могла быть выработана при администрации президента Барака Обамы в силу жестких противоречий с руководством России, то избранный президент США Дональд Трамп не раз заявлял о необходимости совместной борьбы против «ИГ». Такая риторика, в случае ее реального воплощения в политике США, может сыграть положительную роль в деле устранения террористов. Стоит также добавить, что для ослабления позиций «Исламского государства» требуется лишить его финансовой подпитки, которая может поступать из ряда соседних стран, заинтересованных в нестабильности в регионе, а также усилить работу по выявлению фактов продажи нефти террористами и особо крупных денежных потоков, направляемых на территории, занятые боевиками, с целью лишить их материальной основы.

\section{Список литературы}

1. Морозов И.Л. Интернет и терроризм - аспекты взаимовлияния // Научный вестник Волгоградского филиала РАНХиГС. Серия: Политология и социология. Т. 1. № 7. 2012. С. 10-13. 
2. Isis rebels declare 'Islamic state' in Iraq and Syria : [Электронный источник] // BBC News. URL: http://www.bbc.com/news/world-middleeast-28082962

3. Charlie Hebdo attack: Three days of terror: [Электронный источник] // BBC News. URL: http://www.bbc.com/news/world-europe-30708237

4. Suicide attackers in Paris massacre more than 120 at concert hall, restaurants, Stade de France : [Электронный источник] // The National. URL: http://www.thenational.ae/world/europe/suicide-attackers-in-parismassacre-more-than-120-at-concert-hall-restaurants-stade-de-france

5. ISIL claims Brussels attacks : [Электронный источник] // Al Jazeera. URL: http://www.aljazeera.com/news/2016/03/explosions-hit-brusselszaventem-airport-160322072734305.html

6. Nice attack: At least 84 killed by lorry at Bastille Day celebrations : [Электронный источник] // BBC News. URL: http://www.bbc.com/ news/world-europe-36800730

7. Berlin Christmas market: 12 dead, 48 hospitalized in truck crash : [Электронный источник] // CNN. URL: http://edition.cnn.com/2016/12/19/ europe/berlin-christmas-market-truck/

8. В Стамбуле совершено вооружённое нападение на ночной клуб : [Электронный источник] // Russia Today. URL: https://russian. rt.com/world/article/346874-v-stambule-soversheno-vooruzhyonnoenapadenie-na-nochnoi

9. International Migration Outlook 2016. OECD, 2016. 428 p.

10. Маунтер Г. Мигранты и терроризм в Европе: [Электронный источник] // Новое Восточное Обозрение. URL: http://ru.journal-neo. org/2016/10/02/migranty-i-terrorizm-v-evrope/

11. ФСБ: террористы эффективно используют рост числа мигрантов в Европе: [Электронный источник] // РИА Новости. URL: https://ria. ru/world/20160727/1472943038.html

12. Спецслужба халифата : [Электронный источник] // Lenta.ru. URL: https://lenta.ru/articles/2016/08/05/emni/

13. Лавров: создается впечатление, что Запад выгораживает «АнНусру»: [Электронный источник] // РИА Новости. URL: https://ria. $\mathrm{ru} /$ world/20161110/1481076960.html 
14. Statement by the President on ISIL. September 10, 2014 : [Электронный источник] // Office of the Press Secretary of the White House. URL: https://www.whitehouse.gov/the-press-office/2014/09/10/statementpresident-isil-1

15. Соглашение между Российской Федерацией и Сирийской Арабской Республикой о размещении авиационной группы Вооруженных Сил Российской Федерации на территории Сирийской Арабской Республики от 26 августа 2015 года [Электронный источник] // Официальный интернет-портал правовой информации. URL: http://publication. pravo.gov.ru/Document/View/0001201601140019?index=0\&rangeSize $=1$

16. Финансирование террористической организации Исламское государство Ирака и Леванта (ИГИЛ): Отчет ФАТФ. Париж, 2015.

17. Чемпионы по джихаду : [Электронный источник] // Lenta.ru. URL: https://lenta.ru/articles/2014/07/07/isilstory/

18. Ассанж: Клинтон знает, что ИГ финансируется правительствами Катара и Саудовской Аравии: [Электронный источник] // Информационное агенство «TACC». URL: http://tass.ru/mezhdunarodnayapanorama/3758903

19. Васильчук Е.О., Морозов И.Л., Матвенко Е.А. Радикальные политические движения современности: особенности субкультурного стиля // Вестник Волгоградской академии МВД России, 2012. № 2 (21). С. 9-15.

20. Чеченских имамов учат противостоять пропаганде «Исламского государства»: [Электронный источник] // HTB. URL: http://www.ntv. ru/novosti/1459476/

\section{References}

1. Morozov I.L. Internet i terrorizm - aspekty vzaimovlijanija [Internet and terrorism - aspects of interaction]. Nauchnyy vestnik Volgogradskogo filiala RANKhiGS. Seriya: Politologiya i sotsiologiya [Scientific Bulletin of RANEPA, Volgograd branch. Series: Political Science and Sociology]. Vol. 1, № 7. 2012. P. 10-13.

2. Isis rebels declare 'Islamic state' in Iraq and Syria. BBC News. http:// www.bbc.com/news/world-middle-east-28082962 
3. Charlie Hebdo attack: Three days of terror. $B B C$ News. http://www.bbc. com/news/world-europe-30708237.

4. Suicide attackers in Paris massacre more than 120 at concert hall, restaurants, Stade de France. The National. http://www.thenational.ae/world/ europe/suicide-attackers-in-paris-massacre-more-than-120-at-concerthall-restaurants-stade-de-france.

5. ISIL claims Brussels attacks. Al Jazeera. http://www.aljazeera.com/news /2016/03/explosions-hit-brussels-zaventem-airport-160322072734305. html.

6. Nice attack: At least 84 killed by lorry at Bastille Day celebrations. $B B C$ News. http://www.bbc.com/news/world-europe-36800730

7. Berlin Christmas market: 12 dead, 48 hospitalized in truck crash. CNN. http://edition.cnn.com/2016/12/19/europe/berlin-christmas-market-truck/

8. V Stambule soversheno vooruzhjonnoe napadenie na nochnoj klub [An armed attack on a nightclub was committed in Stambul]. Russia Today. https://russian.rt.com/world/article/346874-v-stambule-soversheno-vooruzhyonnoe-napadenie-na-nochnoi

9. International Migration Outlook 2016. OECD, 2016. 428 p.

10. Maunter G. Migranty i terrorizm v Evrope [Migrants and terrorism in Europe]. New Eastern Outlook. http://ru.journal-neo.org/2016/10/02/ migranty-i-terrorizm-v-evrope/

11. FSB: terroristy jeffektivno ispol'zujut rost chisla migrantov $v$ Evrope [FSB terrorists effectively use the growing number of migrants in Europe]. RIA Novosti. URL: https://ria.ru/world/20160727/1472943038. html

12. Specsluzhba halifata [Caliphate's Intelligence Agency]. Lenta.ru. https://lenta.ru/articles/2016/08/05/emni/

13. Lavrov: sozdaetsja vpechatlenie, chto Zapad vygorazhivaet "An-Nusru" [Lavrov: It seems that the West justifies "an-Nusra"]. RIA Novosti. https://ria.ru/world/20161110/1481076960.html

14. Statement by the President on ISIL. September 10, 2014. Office of the Press Secretary of the White House. https://www.whitehouse.gov/thepress-office/2014/09/10/statement-president-isil-1 
15.The official site of legal information. http://publication.pravo.gov.ru/ Document $/$ View/0001201601140019? index $=0 \&$ rangeSize $=1$

16.Finansirovanie terroristicheskoj organizacii Islamskoe gosudarstvo Iraka i Levanta (IGIL): Otchet FATF [Financing of the Terrorist Organisation Islamic State in Iraq and the Levant (ISIL)]. Paris, 2015.

17. Chempiony po dzhihadu [Champions of the jihad]. Lenta.ru. https:// lenta.ru/articles/2014/07/07/isilstory/

18. Assanzh: Klinton znaet, chto IG finansiruetsja pravitel'stvami Katara i Saudovskoj Aravii [Assange: Clinton knows that IS is funded by the Governments of Qatar and Saudi Arabia]. TASS News Agency. http:// tass.ru/mezhdunarodnaya-panorama/3758903

19. Vasil'chuk E.O., Morozov I.L. Matvienko E.A. Radikal'nye politicheskie dvizhenija sovremennosti: osobennosti subkul'turnogo stilja [Contemporary Radical Political Movements: Peculiarities of Subcultural Style]. Vestnik Volgogradskoy akademii MVD Rossii [Bulletin of Volgograd Academy of Russian Ministry of Internal Affairs], 2012. № 2 (21), pp. 9-15.

20. Chechenskih imamov uchat protivostojat' propagande "Islamskogo gosudarstva" [Chechen imams are taught to resist the propaganda of the "Islamic state"]. NTV. http://www.ntv.ru/novosti/1459476/

\section{ДАННЫЕ ОБ АВТОРЕ}

Лобанов Никита Александрович, аспирант

Волгоградский филиал РАНХиГС

ул. Гагарина, 8, г. Волгоград, 400131, Российская Федераџия ngld35@gmail.com

\section{DATA ABOUT THE AUTHOR}

Lobanov Nikita Aleksandrovich, Graduate Student

Volgograd Branch of the Russian Academy of National Economy and Public Administration

8, Gagarin Str., Volgograd, 400131, Russian Federation ngld35@gmail.com 